\title{
The incidence and risk factors for development of lower limb lymphedema after treatment for gynaecological cancers
}

\author{
Noori Khalid ${ }^{1}$, Adarsh Dharmarajan ${ }^{1 *}$, Satheeshan B. ${ }^{1}$, \\ Biji M. S. ${ }^{2}$, Abina S. S. ${ }^{2}$, Remya Binesh ${ }^{1}$
}

\begin{abstract}
${ }^{1}$ Department of Surgical Oncology, ${ }^{2}$ Department of Cancer Palliative Medicine, Malabar Cancer Center, Thalassery, Kerala, India
\end{abstract}

Received: 05 January 2018

Revised: 17 January 2018

Accepted: 31 January 2018

\section{*Correspondence:}

Dr. Adarsh Dharmarajan,

E-mail: dradarshdharmarajan@gmail.com

Copyright: (C) the author(s), publisher and licensee Medip Academy. This is an open-access article distributed under the terms of the Creative Commons Attribution Non-Commercial License, which permits unrestricted non-commercial use, distribution, and reproduction in any medium, provided the original work is properly cited.

\begin{abstract}
Background: The development of postoperative lower limb lymphedema (LLL) is a disabling, yet usually overlooked sequele of most gynecological cancer treatment. It can lead to significant functional problems that negatively affect gynecological cancer survivors' daily living, work, emotional state, and overall quality of life. The objective of this study is to calculate the incidence of lower limb lymphedema in patients undergoing surgery for gynecological cancer and to evaluate the risk factors for its development.

Methods: Women with newly diagnosed carcinoma ovary, carcinoma endometrium and carcinoma cervix, who underwent surgery at a tertiary cancer centre from September 2016 were included in the study. The circumference of both lower limbs was measured at prefixed sites. The limb volume was calculated using the formula $\mathrm{C} 2 / \mathrm{pi}$. A baseline value was taken prior to surgery. The patients were followed up every 3 months and the limb volume were calculated at each visit. An increase in limb volume by $>10 \%$ was defined as lymphedema.

Results: The incidence of lymphedema after 1 year follow up was $43.5 \%$. There was no significant association between known risk factors such as extent of lymphadenectomy ( $\mathrm{p}$ value 0.633 ) number of pelvic or para aortic lymph nodes removed ( $\mathrm{p}$ value 0.69 and 0.44 respectively) and type of adjuvant therapy ( $\mathrm{p}$ value 0.455 ).

Conclusions: The incidence of LLL according to the present study was $43.5 \%$. There was no statistically significant association between development of LLL and risk factors like site and number of lymph nodes removed and type of adjuvant therapy.
\end{abstract}

Keywords: Lower limb, Lymphedema, Gynecological cancer

\section{INTRODUCTION}

After cervical cancer, cancer of the ovary and uterine corpi are the most common gynaecological malignancies affecting women in our country.

With the development of more effective chemotherapeutic agents and regimes the survival of patients with ca ovary has improved. Same holds true for patients with uterine cancer, where combination of surgery, radiotherapy and chemotherapy has made it potentially curable. As more effective modes of treatment, such as extended surgical removal and lymph node dissection are implemented, many patients with ovarian or uterine carcinoma have been cured and survivorship has continued to increase. ${ }^{1}$ However lower limb lymphedema (LLL) continues to be a disabling, yet usually overlooked sequele of such extensive surgeries. 
Acquired lower limb lymphedema (LLL) occurs due to disruption of the lymphatic system leading to increased endlymphatic pressure. Histological changes in the lymphatic vessel ensues and causes accumulation of protein rich lymphatic fluid in the interstitial spaces. ${ }^{2}$

Like primary lymphedema and breast cancer-related lymphedema, lower limb lymphedema related to gynecological cancer is incurable and chronic in nature. Lower limb lymphedema leads to significant functional problems that negatively affect gynecological cancer survivors' daily living, work, emotional state, and overall quality of life as well as leading to financial burdens. Lymphedema can take a psychological toll, with patients experiencing symptoms such as anxiety, depression, and adjustment problems.

Consequently, lymphedema can affect the patients' vocational, domestic, social, and sexual lives and adversely affect their quality of life. ${ }^{3-5}$ Hence prevention and early detection of lymphedema in patients undergoing lymphadenectomy for gynecological cancer should also be an integral part of comprehensive cancer therapy.

The objective of this study is to calculate the incidence of lower limb lymphedema in patients undergoing surgery for gynecological cancer using standardized leg measurements. The study also aims at evaluating the risk factors for development of lymphedema including type of surgery and adjuvant therapy, extend of lymphadenectomy and number of pelvic and para aortic lymph nodes removed.

\section{METHODS}

This was a prospective observational study of patients who had undergone surgery for gynaecological cancers at author's institution. The Institutional review board approved the study. Women with newly diagnosed carcinoma ovary, carcinoma endometrium and carcinoma cervix, who underwent surgery and women who underwent completion surgery at a tertiary cancer centre from September 2016 were included in the study after taking informed consent. The study period was 1 year.

Women with preexisting lower limb edema and those who failed to attend follow up were excluded from the study. Preoperative counselling was done and the risk of developing lower limb lymphoedema was explained. All eligible patients were seen by the co-investigators and the demographic data was collected including age, height, weight, BMI, comorbid illness, histological diagnosis, grade and stage of the disease. The circumference of both lower limbs was measured at prefixed sites starting from $2 \mathrm{~cm}$ above ankle joint, and at every $4 \mathrm{~cm}$ distance using a measuring tape. The limb volume was calculated using the formula $\mathrm{C} 2 / \mathrm{pi}^{6}{ }^{6} \mathrm{~A}$ baseline value was taken prior to surgery.
Preoperative imaging was obtained, and presence of enlarged lymph nodes were noted. All staging work up was done as per institutional protocol. Intra operative findings was recorded, including the extent of lymph node dissection, any intraoperative complications and the stage of the disease.

The patient was monitored in the immediate postoperative period, and any aggravating factors for lower limb lymphoedema was recorded, such as development of anaemia, hypoproteinemia, cardiac failure, DVT. Limb girth was measured again on day 5/day 6. After discharge patients were evaluated at every 3 months in the OPD for follow up. The lower limb measurements were repeated at these prefixed points and limb volume was calculated at each visit. The same nurses measured the limb at each visit.

Histopathology report was obtained. The number of lymph node removed, and node positivity was noted. The type of adjuvant treatment taken, if any, was also recorded. Lymphoedema was defined as a difference in limb volume more than $10 \%$ than the preoperative baseline. $^{6}$

Patients were sent to the lymphedema clinic to confirm the diagnosis and for management. Patients who developed lymphedema were staged according to the International society of Lymphology staging. (<20\% mild, $20-40 \%$ moderate, $>40 \%$ severe). ${ }^{6}$

\section{RESULTS}

26 patients were enrolled in the study. One patient expired in the course of treatment due to complications related to adjuvant treatment. Two patients failed to review for follow-up hence these 3 patients were removed from study. 23 patients who underwent surgery for gynaecological cancers in the year 2016 were followed up for a period of 9 months to 1 year.

Table 1: Patient characteristics.

\begin{tabular}{|ll|}
\hline Variable & Number $(\%)$ \\
\hline $\begin{array}{l}\text { Age } \\
\text { Diagnosis }\end{array}$ & Median $52(38-74$ years $)$ \\
\hline Ca endometrium & $10(43.5)$ \\
\hline $\begin{array}{l}\text { Epithelial ovarian cancer } \\
\text { Ca cervix }\end{array}$ & $10(43.5)$ \\
\hline $\begin{array}{l}\text { Synchronous ovarian and } \\
\text { endometrial Ca }\end{array}$ & $2(8.7)$ \\
\hline BMI & $1(4.3)$ \\
\hline$<18.5$ & $2(8.7)$ \\
\hline $18.5-24.9$ & $13(56.5)$ \\
\hline $25-29.9$ & $7(30.4)$ \\
\hline $30-35$ & $1(4.3)$ \\
\hline Comorbidities present & $14(60)$ \\
\hline Yes & $9(40)$ \\
\hline No & \\
\hline
\end{tabular}




\section{Demographics}

The median age of the patients enrolled in the study was 52 years. There were 10 patients with epithelial ovarian cancer of which 7 was $\mathrm{Ca}$ ovary, 2 were primary peritoneal carcinoma and 1 was $\mathrm{Ca}$ Fallopian tube. 10 patients with $\mathrm{Ca}$ endometrium and 3 with $\mathrm{Ca}$ cervix. 1 patient had a synchronous ovarian and endometrial cancer. BMI was calculated, and 2 patients were found to be underweight. 13 had normal weight, whereas 7 were found to be overweight and 1 obese. 14 patients had co morbidities (Hypertension: 4, Diabetes mellitus: 4, Hypothyroidism: 3, both diabetes + Hypertension: 1, Others: 2)

\section{Treatment received and pathology findings}

All the patients with Epithelial ovarian cancer and $\mathrm{Ca}$ endometrium underwent staging laparotomy including systematic lymphadenectomy in the form of bilateral pelvic and paraaortic lymph node dissection. Of this, 5 patients underwent only pelvic lymphadenectomy while the rest of the 18 patients underwent pelvic and para aortic lymph node dissection (Table 2).

Table 2: Treatment details.

\begin{tabular}{|ll|}
\hline Extend of lymphadenectomy & Number \\
\hline B/L pelvic lymph node dissection & 5 \\
\hline $\begin{array}{l}\text { B/L pelvic and para aortic lymph node } \\
\text { dissection }\end{array}$ & 18 \\
\hline Total & 23 \\
\hline Adjuvant therapy & \\
\hline Vaginal brachytherapy (VBT) & 5 \\
\hline VBT + EBRT & 1 \\
\hline Chemotherapy & 11 \\
\hline None & 6 \\
\hline Total & 23 \\
\hline
\end{tabular}

Intraoperative bulky nodes were found in 8 patients; however, the nodes were found to be positive on histopathology only in 4 patients. Mean number of pelvic lymph nodes removed was 19 and mean number of para aortic lymph nodes was 12 . Postoperatively, based on the histopathology findings, 16 patients required adjuvant treatment in the form of radiation therapy or chemotherapy. Of these 6 patients required radiation therapy: 5 of them received vaginal brachytherapy (VBT) alone and 1 received external beam radiotherapy (EBRT) along with VBT (Table 2).

\section{Statistical analysis}

The collected data was entered in MS Excel and analyzed using R-software. The demographic variables such as age were represented using Arithmetic mean and standard deviation. Appropriate diagrams were also used for representing the results. The possible associated risk factors for development of lymphedema was tested using Fishers exact test. The incidence of lymphedema at $3^{\text {rd }}$ month of follow up was $22 \%(5 / 23)$ and at $6^{\text {th }}$ month it was $30 \%$. By 1 year the incidence was $43.5 \%(10 / 23)$ (Figure 1, Figure 2).

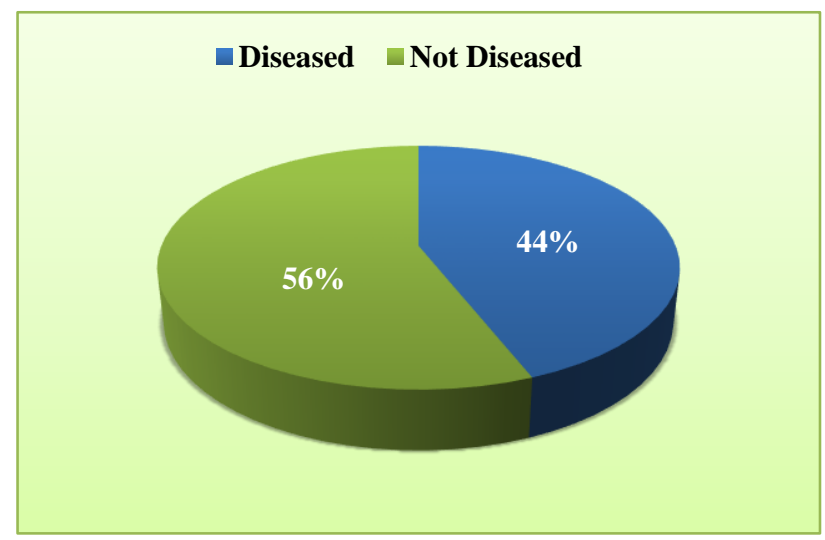

Figure 1: Incidence of Lymphedema.

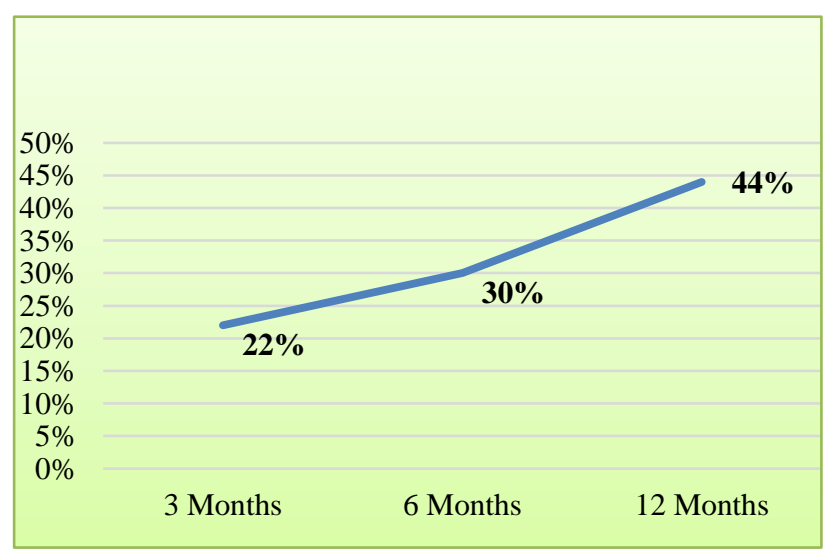

Figure 2: Trend of disease occurrence.

Table 3: Extent of lymphadenectomy and lymphedema.

\begin{tabular}{|c|c|c|c|c|}
\hline & & \multicolumn{2}{|c|}{ Lymphedema } & \multirow{2}{*}{ Total } \\
\hline & & No & Yes & \\
\hline \multirow{4}{*}{ Extend of lymphadenectomy } & \multirow{2}{*}{$\mathrm{B} / \mathrm{L}$ pelvic and para aortic lymph node dissection } & 10 & 8 & 18 \\
\hline & & $55.6 \%$ & $44.4 \%$ & $100.0 \%$ \\
\hline & \multirow{2}{*}{$\mathrm{B} / \mathrm{L}$ pelvic lymph node dissection } & 3 & 2 & 5 \\
\hline & & $60.0 \%$ & $40.0 \%$ & $100.0 \%$ \\
\hline
\end{tabular}


5 patients had unilateral lymphedema and the rest 5 had bilateral. The severity of lymphedema was also calculated. The stage of lymphedema was mild in 6 patients $(60 \%)$ where the increase in limb volume was $<20 \%$. The rest of $4(40 \%)$ patients had moderate lymphedema where the increase in limb volume was between $20-40 \%{ }^{6}$

The role of site and extent of lymphadenectomy in causing lymphedema was analysed No significant association were found between extent of lymphadenectomy and Incidence of lymphedema. $p$ value $=0.633$ (Table 3 ).

The mean number of pelvic lymph nodes removed in patients with lymphedema was 19.9 and in patients without lymphedema it was 18.4. Similarly, the mean para aortic lymph nodes removed in patients with lymphedema was 10.5 and in those without was 14.0 (Table 4).

Table 4: Association with number of lymph nodes removed and lymphedema.

\begin{tabular}{|l|lcl|}
\hline & Diseased & \multicolumn{3}{c}{$\begin{array}{l}\text { Not } \\
\text { diseased }\end{array}$} & $\begin{array}{l}\text { P } \\
\text { value }\end{array}$ \\
\hline $\begin{array}{l}\text { Site of } \\
\text { lymphadenectomy }\end{array}$ & $\begin{array}{l}\text { Mean number of lymph nodes } \\
\text { removed }\end{array}$ \\
\hline Pelvic & 19.9 & 18.4 & 0.693 \\
\hline Para aortic & 10.5 & 14.0 & 0.442 \\
\hline
\end{tabular}

There was no statistically significant association between number of lymph nodes removed and development of lymphedema. $\mathrm{P}$ value was 0.69 and 0.44 for pelvic and para aortic lymph nodes, respectively (Table 4).

The association of the type of adjuvant treatment received with the development of lymphedema was studied. 16 patients received adjuvant treatment and 6 of this received radiation therapy.

Table 5: Association of type of adjuvant and lymphedema.

\begin{tabular}{|c|c|c|c|c|}
\hline & \multicolumn{2}{|c|}{$\begin{array}{l}\text { Lymphedema } \\
1 \text { year }\end{array}$} & \multirow[t]{2}{*}{ Total } \\
\hline & & No & Yes & \\
\hline \multirow{8}{*}{$\begin{array}{l}\text { Type of } \\
\text { adjuvant } \\
\text { therapy }\end{array}$} & \multirow{2}{*}{ No adjuvant } & 4 & 2 & 6 \\
\hline & & $66.7 \%$ & $33.3 \%$ & $100.0 \%$ \\
\hline & \multirow{2}{*}{$\begin{array}{l}\text { Radiation } \\
\text { therapy }\end{array}$} & 4 & 1 & 5 \\
\hline & & $80.0 \%$ & $20.0 \%$ & $100.0 \%$ \\
\hline & \multirow{2}{*}{ Chemotherapy } & 5 & 6 & 11 \\
\hline & & $45.5 \%$ & $54.5 \%$ & $100.0 \%$ \\
\hline & \multirow{2}{*}{$\begin{array}{l}\text { Chemo + } \\
\text { Radiation }\end{array}$} & 0 & 1 & 1 \\
\hline & & $0.0 \%$ & $100.0 \%$ & $100.0 \%$ \\
\hline
\end{tabular}

There was no statistically significant association between type of adjuvant treatment and the incidence of
Lymphedema. $\mathrm{P}$ value $=0.455($ Fishers Exact test $)($ Table $5)$.

\section{DISCUSSION}

Our study revealed that the incidence of lymphedema at 1 year of follow-up was $43.5 \%$. Various studies have reported the prevalence of lower limb lymphedema after cancer surgery in the range of $1-49 \% .^{7}$ This vast range is attributed to the variations in lymphedma defenitions, lymphedema measures, type of gynecological cancer and time to assess lymphedema onset after cancer surgery. ${ }^{7}$ The high incidence reported in present study could be attributed to a more stringent cut off of $10 \%$ increase in limb volume to define lymphedema. A prospective pilot study conducted by Hopp EE et al showed $12.8 \%$ incidence of postoperative lower limb lymphedema in women with endometrial cancer. Here the diagnosis of lymphedema was done based on an increase in limb measurements by $20 \%{ }^{8}$ In the present study only 3 patients out of the 23 had an increase in limb volume of more than $20 \%$ which would bring down our incidence rate to $13 \%$ which is comparable to the above study.

Research has identified many risk factors for development of LLL, and this includes removal of lymph nodes, post-operative radiotherapy, and other factors. Removal of pelvic lymph nodes can significantly reduce the flow of lymphatic fluid from the lower limbs. Postoperative radiotherapy was found to be an independent risk factor for lower limb lymphedema. ${ }^{9}$ For the site of lymph nodes, removal of groin lymph nodes in vulvar cancer was associated with a higher incidence of lymphedema compared to removal of para aortic lymph nodes in ovarian cancer. ${ }^{10-12}$ Another study by Ki EY et al revealed that pelvic node dissection increased the risk of LLL after surgery compared to no pelvic node dissection, but para-aortic node dissection did not increase the risk of LLL compared to pelvic node dissection alone. ${ }^{13}$

Present study group did not include patients with vulvar cancer, hence an association of groin node dissection in development of LLL could not be done. However, in the present study did not find any statistically significant difference in the incidence of lymphedema in patients undergoing pelvic lymph node dissection alone compared to those who underwent pelvic and para aortic lymph node dissection. Many studies have analysed the significance of the number of lymph node dissected in the development of lymphedema. Rustum A et al suggested that the number of resected LNs $>10$ is associated with LLL after surgery in uterine carcinoma. ${ }^{14}$ In their study, the mean number of resected LNs was 20.7. Another study by Fuller et al documented that removal of more than $25 \mathrm{LNs}$ leads to development of LLL in cervical cancer. ${ }^{15}$ Present study did not reveal any association with number of lymph nodes removed and development of LLL. Post-operative radiation was found to be a risk factor for occurrence of LLL among cervical and uterine cancer patients who underwent pelvic lymph node 
dissection. ${ }^{7,9}$ Present study involved a small number of patients who underwent any form of adjuvant therapy. Only 6 patients received radiation therapy and we did not find any significant association in development of lymphedema in these patients.

Most of the studies published on postoperative LLL were retrospective in nature. The diagnosis of lymphedema in many of these studies was done with the help of questionnaires or with patient-reported or physicianreported swelling of lower limbs. ${ }^{7,9,14}$ Present study was a prospective observational study with all the study subjects undergoing serial limb measurements and this has helped in the early detection of lymphedema. The incidence of lymphedema is quite high according to our study and this undermines the importance of proper preoperative counseling and education regarding this disabling side effect of gynecology cancer treatment.

The small sample size and the short period of follow up of 1 year were the limitations of the present study. The secondary morbidities associated with LLL can be quite disabling and can have serious consequence on the quality of life. These issues were not addressed due to the short follow up period and this was another drawback of the study.

\section{CONCLUSION}

Present study demonstrated that the incidence of postoperative lower limb lymphedema is $43.5 \%$ in patients undergoing treatment for gynaecological cancer. The development of lymphedema was not affected by the extent of lymphadenectomy number of lymph nodes removed or by the type of adjuvant therapy according to present study. However, a bigger sample size with a longer follow-up period of at least 2 years is required to come to definite conclusion regarding the association of risk factors in the development of lower limb lymphedema. A quality of life survey will also help to identify the secondary morbidities and also give us critical information for effective counselling and patient education prior to surgery.

Funding: No funding sources Conflict of interest: None declared

Ethical approval: The study was approved by the Institutional Ethics Committee

\section{REFERENCES}

1. Soisson AP, Soper JT, Clarke-Pearson DL, Berchuck A, Montana G, Creasman WT. Adjuvant radiotherapy following radical hysterectomy for patients with stage IB and IIA cervical cancer. Gynecol Oncol. 1990;37:390-5.
2. Mihara, M, Hara H, Hayashi Y. Pathological steps of cancer-related lymph- edema: histological changes in the collecting lymphatic vessels after lymphadenectomy. PLoS One. 2012;7(7):e41126.

3. Newman ML, Brennan M, Passik S. Lymphedema complicated by pain and psychological distress: a case with complex treatment needs. J Pain Symptom Manage. 1996;12:376-9.

4. Rockson SG. Lymphedema. Am J Med. 2001;110:28895.

5. Carter BJ. Women's experiences of lymphedema. Oncol Nurs Forum. 1997;24:875-82.

6. Morgan PA, Moffat CJ. International consensus on managing lymphoedema. Nurs Times. 2006;102:42-4.

7. Beesley V, Janda M, Eakin E, Obermair A, Battistutta D. Lymphedema after gynecological cancer treatment: prevalence, correlates, and supportive care needs. Cancer. 2007;109(12):2607-14.

8. Hopp EE, Osborne JL, Schneider DK, Bojar CJ, Uyar DS. A prospective pilot study on the incidence of postoperative lymphedema in women with endometrial cancer. Gynecol Oncol Rep. 2016;15:25-8.

9. Tada H, Teramukai S, Fukushima M, Sasaki H. Risk factors for lower limb lymphedema after lymph node dissection in patients with ovarian and uterine carcinoma. BMC Cancer. 2009; 9:47

10. Ryan M, Slaytor EK, Jaconelli C. Aetiology and prevalence of lower limb lymphoedema following treatment for gynaecological cancer. Aust N Z J Obstet Gynaecol. 2003;43:148-51.

11. Achouri A, Huchon C, Bats AS. Postoperative lymphocytes after lymphadenectomy for gynaecological malignancies: preventive techniques and prospects. Eur J Obstet Gynecol Reprod Biol. 2012;161:125Y129.

12. Tiwari P, Salani R, Povoski SP. Breast and gynecologic cancer-related extremity lymphedema: a review of diagnostic modalities and management options. World $\mathbf{J}$ Surg Oncol. 2013;11:237-49.

13. Ki EY, Park JS, Lee KH, Hur SY. Incidence and risk factors of lower extremity lymphedema after gynecologic surgery in ovarian cancer. Int $\mathbf{J}$ Gynecol Cancer. 2016;26:1327-32.

14. Abu-Rustum NR, Alektiar K, Iasonos A, Lev G, Sonoda Y, Aghajanian C, et al. The incidence of lowerextremity lymph-edema following treatment of uterine corpus malignancies: a 12-year experience at Memorial Sloan-Kettering Cancer Center. Gynecol Oncol. 2006;103:714-8.

15. Fuller J, Guderian D, Kohler C. Lymphedema of the lower extremities after lymphadenectomy and radiotherapy for cervical cancer. Strahlenther Onkol. 2008;184:206Y211.

Cite this article as: Khalid N, Dharmarajan A, Satheeshan B, Biji MS, Abina SS, Binesh R. The incidence and risk factors for development of lower limb lymphedema after treatment for gynaecological cancers. Int J Reprod Contracept Obstet Gynecol 2018;7:1168-72. 